\title{
CONSTRUÇÃO E DESTRUIÇÃO NA DRAMATURGIA DE OSWALD DE ANDRADE E MELSON RODRIGUES
}

\author{
Marta Morais da Costa
}

\section{INTRODUCAัO}

De inicio, torna-se imperioso delimitar o âmbito deste estudo. Do conjunto de textos de cada um dos dramaturgos em cotejo, procuramos selecionar aqueles que apresentassem um elemento comum que nos permitisse compará-los. $\mathbf{E}$ este aspecto se foi delineando pelo processo de (re) leitura dos textos. Assim, terminamos optando pelo tema CONSTRUÇÃO E DESTRUIÇÃO NA DRAMATURGIA DE OSWALD DE ANDRADE E NELSON RODRIGUES. E dividimo-lo em duas massas: a semântica, em que a dicotomia está representada na oposição constante AMOR (VIDA) X MORTE, ou, segundo Norman Brown, ${ }^{1}$ Eros e Tânatos. A segunda grande divisão, relacionada ao elemento formal, apresenta a dualidade vincada na COMPOSIÇĀO PARATÁTICA X COMPOSIC̣AO HIPOTÁTICA dos textos.

Assim sendo, restringir o material a nosso dispor foi uma questão de bom-senso. Em Oswald de Andrade, $A$ morta possui ambos os ingredientes de nossa proposição e ainda outro, importantíssimo: é um texto que se contesta a si mesmo, através da função metalingüística (metateatro ${ }^{2}$ ).

Em Nelson Rodrigues fomos buscar Vestido de Noiva, $O$ Anjo Negro e Album de Famíıia, o que não impedirá que fa-

(1) BROWN, Norman. Vida contro morte. Fetrópolis, Vozes, 1972 (Coleşäo Contracultura, 2 ).

(2) ABEL, Lionel. Metatoztro: uma visāo nova da forma dramática. Rio, Zahar, 1968. 
çamos referência a outras peçıs de sua autoria. Por que estas três peças? Em primeiro lugar, porque atendiam ao intuito deste estudo. Em segundo, por suas variantes particulares: na primeira, o inconsciente; na segunda, a união bem sucedida Eros-Tânatos; na terceira, a perversão de Eros.

Estamos conscientes da dificuldade de se fazer um estudo comparativo. Principalmente porque neste tipo de abordagem é muito freqüente encontrar-se antes diferenças do que semelhanças. $E$ que, o critério de valor, que se venha a emitir, seja apenas a expressão parcial de seu verdadeiro valor.

1. o conflito eros/tânatos

1.1. Posicionamento dos autores

Oswald de Andrade

a. "Da equação eu parte do Cosmos, ao axioma Cosmos parte to eu."

b. "Contra a realidade social, vestida e opressora, cadastrada por Freud - a realidade sem complexos, sem loucura, sem prostituiçōes e sem penitenciárias do matriarcado de Pindorama."

c. "A morta é o drama do poeta; do coordenador de toda ação humana, a que a hostilidade de um século reacionário afastou pouco a pouco da linguagem útil e corrente (...) As catacumbas líricas ou se esgotam ou desembocam nas catacumbas politicas."

Nelson Rodrigues

"remontei em Vestido de Noiva o velório de minha infância $\mathbf{E}$ por todo o meu teatro há uma palpitação de sombras e de luzes. De texto em texto a chama de um círio passa a outro círio, numa obsessão feérica, que para sempre me persegue."

(3) ANDRADE, Oswald de. Manifesto antropófago. In: - - - O- Obras compleles. Rio. Civilizaşäo Brasi'eir a, 1973, v. 6. D. 35.

(6) RODRIGUES, Nelson. Memórias de Nelson Rodrigues. Rio, Tompo Brasileiro, 1967. p. 147.

(4) Ibid., p. 19.

(5) ANDRADE, Oswald de. Carta-prefácio do autor. In: ------. Obres cempletzs: Teatro. Rio, Civilizaçäo Brasileira, 1973. v. 8, p. 3. 


\subsection{No "país do individuo"}

Partem, ambos os dramaturgos, do plano do individuo. Nelson Rodrigues o vê como o fantasma de sua obsessão e de sua própria vivência. Alaíde (VN), pelo processo de manifestação do subconsciente de seu drama, está repetida em Sônia (V6). Jonas, devorado por um amor incestuoso, tem em Senhorinha seu "duplo" feminino (AF). Este amor incestuoso que existe em latência em Virgínia (AN). E em toda sua obra há uma rede de incestos e adultérios, de amantes e mal-amados, frutos da repressão sexual do indivíduo.

São diferentes os personagens de Oswald de Andrade. São sempre indivíduos em relacionamento dialético com a realidade e com a sociedade, a ponto de se desindividualizarem para serem vistos ou como uma classe social: "uma barricada de abelardos" (RV), ou sem um antropônimo a identificá-lo: a Poeta (M), ou representando um mito pagão ou cristão: Icar (o) e S. Pedro (HC). Oswald filtra marxistamente a sua obra, o que dilui a problemática individual dos personagens, numa atitude aproximada à dos surrealistas em quem "a influência de Marx leva a arte de investigação do subconsciente para instrumento de agitação social". ${ }^{B}$

Assim, não se aceita como definitiva a afirmação de que Nelson Rodrigues e Oswald de Andrade têm a mesma abordagem freudiana do personagem. A diferença entre o enfoque marxista e o freudiano esta em que "a psique é (para Marx) um reflexo do método de produção da vida material", e para Freud "a estrutura social constitui um reflexo dos conteúdos psiquicos"."

Este marxismo revela-se na tentativa do Poeta (M) em manter-se consciente e assim ser capaz de destruir a repressão representada por Beatriz e "O país da anestesia", recusando-se a aceitá-los: "Não mais estes símbolos dialéticos

(7) Esclareccmos, a seguir. as convenģöes adotedas neste estudo para a titulosāo de peças. a. De Oswald de Andrade:

(M) A morta; (RV) O roi da vela; (HC) O homem - O cavalo.

b. De Nelson Rodrigues:

(MP) A mulhor som pocado; (VN) Vostido do noiva; (AF) Album do fo milia; (AN) Anjo negro; (SA) Senhora dos afogados; (V6) Valsa n.0 6; (BA) O beijo no asfalto; (PT) Perdoa-me por me tralres; (BO) Bonitinha mas ordinária; (F) A falocida.

(B) TELLES,Gilberto Mendonça. O surrealismo. In: --_---. Vanguarda européie - modernismo brasileiro. Petrópo iis, Vozes, 1972. p. 124.

(9) ROSZAK, Theodore. A eenlrzeuitura. 2 ed. Petrópolis, Vozes, 1972. p. 95 (Coleçäo Con tracultura, i) 
do sexual perturbarão a marcha do homem terreno." (M, p. 55). Ou: "Devoro-ie trecho noturno de minha vida! Serei fiel para com os arrebóis do futuro..." (M, p. 56).

Reaparece em (M) a proposição de um paraiso terrestre marxista (utópico ou nāo), estruturador de sua dramaturgia: os jujubas (RV), "A verdade na boca das crianças" (HC).

Já, em Nelson Rodrigues, a repressão não é fruto da neurose social, mas sim da neurose do indivíduo. Freud: "A essência da sociedade é a repressāo do individuo e a essência do individuo é a repressão de si mesmo." ia

Embora pareça haver a presença da sociedade-repressāo em $O$ beijo no asfalto, ela se concretiza primordialmente no plano individual: Jelegado Cunha e Repórter Amado e Arandir-Aprigio.

Na afirmação de Décio te Almeida Prado, referente a Vestido de Noiva, mas extensivo a toda dramaturgia nelsoniana: "Na relação sexual entre os personagens sempre há um elemento equivoco, mórbido, que vem perturbar a pureza do impulso". Daí o fruto proibido, o pecado. "É um estudo do que há de menos límpido no coração do homem, esse amor ao pecado, ao remorso, à auto-punição." Configura-se, portanto, a dramaturgia nelsoniana como um contínuo "panorama de análise" freudiano que, em Oswald, só existe numa primeira fase, extrapolada, num segundo momento: cf. a passagem de "O país do individuo" para o "País da Gramática".

Outro dado que corrobora a diferença acima apontada está em que, o "panorama de análise" de "O país do individuo" não subsiste nos "países" subsequentes. Mas, em Neison Rodrigues, aquele panorama está presente em toda a sua obra (a falta de sol no cenário de Anjo Negro é a configuração deste processo psicanalítico contínuo). A maior amplitude do enfoque dado por Oswald de Andrade ao problema do ser-no-mundo também se apóia no fato que, em "O país da anestesia", um dos grupos de personagens é formado por uma familia morta pelo pai, com alusões a traição, amantes e assassínio. Famílias e/ou situacões como esta, constituem o motivo-base da obra de Nelson Rodrigues.

(10) Brown, p. 17.

(ii) PRADO, Decio de Alme da. Apresentusäo do tastro brasileiro modarno: crifica teatral (1947.1955). S. Pav'o, Martins, /1956/ p. 16. 


\subsection{O subconsciente, $o$ amor $e$ a morte.}

Para Freud, nossos verdadeiros desejos são inconscientes e a "neurose geral da humanidade" é causada pela repressão social e/ou individual a esses desejos, que são então recalcados. "Repressāo é a recusa do ser humano em admitir as realidades de sua natureza humana." $\mathrm{E}$ o movimento do espírito humano se fundamenta no princípio do prazer (governado por Eros) e no da realidade (governado pelo eu consciente).

$\mathrm{E}$ "na teoria psicanalítica, os dualismos que estorvam a interação humana com o mundo decorrem não da relação sujeito-objeto, mas do dualismo dos instintos no interior do sujeito." $\mathrm{E}$ estes dois instintos são Eros, o instinto geral de vida, em busca de preservá-la. e Tânatos, o instinto de separação e expulsão, agressivo, independente. Correspondem, respectivamente, a sexo e Violência. Coexistem no homem e geram-lhe a angústia: "nossa vida continua uma luta entre vida e morte, e enquanto durar esse conflito, a angústia também durará."14

Esta angústia é força motriz de $A$ morta. A angústia da criação poética: uma adesão ao convencional ou uma independência e uma inovação, que significa a morte do convencional. Na dramaturgia de Nelson Rodrigues esta angústia é fruto único e exclusivo do sexo, que gera dependência e insatisfação porque sempre reprimido. Assim, fatalmente predomina o instinto de desagregação: a Morte.

Em Oswald de Andrade, a angústia se manifesta na "de. sorganização" da ação dramática: linguagem teatral elíptica, simultaneista, caótica (M); na impossibilidade do Poeta conciliar sua alma (Beatriz) e seu eu social.

Esta "desorganização" aproxima-se daquela de Vestido de Noiva: (con)fusão dos três planos na mente de Alaíde, relacionada muito mais a uma angústia repressiva - p.e., ao tentar ocultar a Mulher de Véu - do que ao problema da organização da linguagem literária. Nesta peça, aniquilamento e vida, morte e amor, coexistem na ação dramática num contraponto constante: a intersecção do plano da realidade no da memória e no da alucinação. Esta intersecção rompe com a linearidade formal (existente em AN e AF) para es-

(12) Brown, p. 19.

(13) Ibid., p. 71 .

(14) Brown, p. 359 
tabelecer a simultaneidade temporal e dramática. $\mathrm{E}$ foi esta simultaneidade (esta "linguagem teatral nova") e mais o seu diálogo fluente e coloquial que se saudou como legitima inovação nos idos de 40 , como a "lufada renovadora da dramaturgia contemporânea".' ${ }^{\text {s }}$

No texto de $A$ morta, percebe-se claramente a paródia à Divina Comédia, de Dante Alighieri: Beatriz, o Poeta, Horácio/Virgílio, a tripartição dos "paises". Mas Beatriz não é, como a homônima de Dante, o guia do poeta na região do Paraiso, ao encontro do Ser e da Vida. Ela é, isto sim, a causa da angústia que impele o Poeta ao mundo abissal de seu subconsciente e de seu sexo. Para chegar ao Paraiso Oswaldiano, o Poeta deve libertar-se de Beatriz. Esta negação da Alma em favor de uma práxis diferencia $A$ morta da obra de Dante e da obra de Nelson Rodrigues.

A morte em Nelson Rodrigues está indissoluvelmente ligada ao Amor. Um dos "leitmotivs" de sua dramaturgia é o dos amantes que desejam morrer juntos: Mme. Clessi e seu namorado (VN); Glória e Teresa, Guilherme e Glória (AF); Virginia e Elias (AN). Isto porque, para o dramaturgo, amor é sinônimo de posse sexual exclusiva (visão antimarxista) e o adultério é um ultraje ao possuidor legal, mesmo que esta posse seja apenas virtual: Glória e Teresa, Guilherme e o "acidente" (AF). Observa-se nesta posição de Nelson Rodrigues a reafirmação da ideologia capitalista da propriedade privada. Isto pode ser comprovado nas seguintes falas:

Jonas - Quando se ama, deve-se possuir e matar a mulher. (AF, p. 351)

Elias - Seria tão bom que você (Virginia) morresse; assim nem ele, nem nenhum homem - ninguém mais tocaria em você... (AN, p. 406)

E por causa desta visão do Amor, que paira sempre sobre os amantes o temor-morte, numa visão sado-masoquista da relação amorosa:

Virginia - Ainda hoje tenho medo (de Ismael) - um medo de animal, de bicho! (AN, p. 392)

Virginia - (para Ismael) Talvez não gostes de amar assim. Talvez precises que eu tenha medo. Talvez queiras sentir o gosto de sangue nos dentes. (AN, p. 426)

(15) MAGALDI, Ssbato. O desbravador. In: _-_-_-_. Panorams do teatro brasileiro. 5. Paulc, Difusös Européis, 1962. p. 202-203 (Corpa e Alma do Brasil, 9). 
Trata-se de característica puramente freudiana, porquanto "o sadismo representa uma extroversão do instinto inato da morte, uma transformação do desejo de morrer em desejo de matar, transformação realizada por Eros de modo a reduzir a tendência inata autodestrutiva do organismo e transformá-la num último aliado na tarefa erótica de manter e enriquecer a vida."

Portanto, é uma forma de equilíbrio, de reencontro com a vida. Nāo há na dramaturgia nelsoniana exemplo melhor do que Virgínia e Ismael (AN) que, pela morte dos filhos, reencontram-se e reencontram a Vida. Em outros momentos porém a auto-destruição completa-se: Olegário (MP), Misael (SA), Guilherme e Jonas (AF).

Já em Oswald, a destruição do incêndio final, que é um ato de sadismo, não possui o significado dramático e emocional existente nas peças de Nelson Rodrigues. $\mathbf{t}$, antes, um ato de afastamento, de negação da ação poética anterior. $O$ Poeta vai ao encontro do povo, da linguagem anti-retórica. Troca o sexual pelo social, o teatro de "panorama de análise" pelo "teatro de estádio". E deixa, na fala do Hierofante, o rastro da destruição dos personagens, da peça e do público: "Se quiserdes salvar as vossas tradiçōes e a vossa moral, ide chamar os bombeiros (...) e talvez vos salvareis da fogueira acesa do mundo." (M, p. 56)

O Poeta, ser consciente, é o único que transita vivo pelo "reino dos mortos", porque só ele tem condições de fugir à repressão. Guardadas as proporções (social-sexual), o Poeta de $A$ morta encontra em Senhorinha, de Album de Família, o seu "duplo."

\subsection{A negação dos códigos sociais}

\subsubsection{O código social.}

Na medida em que são ambos denunciantes da realidade, o código social tende a ser contestado. Em Nelson Rodrigues, a tentativa de desmistificação dos padrões éticos da sociedade burguesa, redunda, por vezes na própria afirmação destes mesmos padrões. A aberração sexual é sempre vista como um crime, e como tal deve ser extirpada pela morte. Raras vezes o inocente sofre uma injustiça ou é castigado. Se os personagens são punidos é porque carregam consigo uma hediondez oculta: Ana Maria (AN), Guilherme, Jonas e Edmundo (AF),

(16) Brown, p. 103. 
Alaíde (VN), Zulmira (F). Em entrevista concedida à revista Veja, datada de 13 de março de 1974, Nelson afirma sentir "uma profunda e inconsolável nostalgia da pureza (...) inclusive a física." Todos os seus personagens, portadores de anomalias sexuais e morais sofrem portanto castigos terríveis para purgarem seus "perados". numa retomada da posição maniqueísta cristã de Bem $/ \mathrm{mal}$.

Quanto à dramaturgia de Oswald de Andrade, pode-se afirmar com segurança que o tom irônico e paródico de suas peças teatrais realiza uma profunda contestação do código social, porque ridiculariza a sociedade de dentro para fora, naquilo que ela tem de mais particular e intimo. Ao ridicularizar, ele mostra a outra face dos acontecimentos, valendo-se da surpresa e da novidade do enfoque: a cena do tribunal (HC), o céu (HC), o segundo ato de O rei da vela. E o riso, característica exclusivamente humana, provocado pelo cômico de situações e de palavras é uma forma de reencontro com a Vida, com o Prazer. Mas é, ao mesmo tempo, uma terrivel arma de crítica e de desvendamento do mecânico e rotineiro da vida humana. $E$ assim sendo, é instrumento de acusação, de ruptura com a "ideologia da seriedade"," de ataque ao contexto social a que pertencem autor e espectadores.

Em "O pais da anestesia", a Senhora Ministra, o Atleta Completo, Caronte chegando num autogiro, ou o Urubu de Edgar sāo exemplos metonímicos de uma sociedade e de uma cultura institucionalizadas, colocadas em função que não lhes é própria e que, portanto, as destrói.

\subsubsection{O código familiar}

O amor e o ódio só podem existir com toda intensidade, na dramaturgia de Nelson Rodrigues, no seio da família.

Edmundo - Mãe, às vezes eu sinto como se o mundo estivesse vazio, e ninguém mais existisse, a não ser nós, quer dizer, você, papai, eu e meus irmãos. Como se a nossa família fosse a única e a primeira (uma espécie de histeria). Então o amor e o ódio teriam de nascer entre nós. (AF, D. 325).

Realmente fundamental esta fala para se estabelecer os

(17) NEVES, Luiz F. Baêta. A ideologia da seriedade e o paradoxz do coringa. Revisis Voxes, Petrópolis, 68(1): 35-40, ian./fev. 1974. 
níveis relacionais dos personagens de Nelson Rodrigues; como novos Adões e Evas no inicio da Criação, eles só têm a si mesmos para amar e torturar. Album de familia está todo estruturado em torno desta fala. Mas outras obras contêm exemplos semelhantes: Lúcia e Alaíde, irmãs, em disputa do amor de Pedro (VN); Aprígio, Dália e Selminha, pai e filhas, desejando o amor de Arandir; Ismael e Elias, irmãos, amando Virgínia e Ana Maria, mãe e filha (AN) ; Raul e Gilberto, irmãos, desejando Judite e Glorinha, mãe e filha (PT); Moema e Misael, pai e filha, e Paulo e Eduarda, mãe e filho (A), e outros.

A família é o núcleo da repressão, é o universo fechado e incestuoso onde todos os dramas eclodem.

Oswald, em $O$ rei da vela, também apresenta uma familia nos moldes daquela de Jonas ( $A F$ ), mas o tratamento que lhe dá é bem outro. A família representa a decadência da sociedade burguesa, da "aristocracia do café", e a denúncia da opressão econômica e política, representada na figura do Americano, é primordial na peça; as aberraçōes sexuais da família do Coronel Belarmino são apresentadas por Oswald com uma complacência tropical.

O traço freudiano de relacionamento familiar é reforça do, na obra de Nelson Rodrigues, pela insegurança e pela fixação edipiana dos personagens:

Edmundo - Eu acho que o homem não devia sair nunca do útero materno, devia ficar lá, toda a vida, encolhidinho, de cabeça para baixo, ou para cima, de nádega, não sei. (AF, p. 325).

Daí a fatal fixação amorosa na figura da mãe cu da mulher mais velha: Mme. Clessi e seu namorado (VN).

Como Oswald de Andrade enfrenta este problema?

Em Oswald, em A morta encontramos:

Beatriz - "Por que nasci? Me digam? Me explique? Não queria nascer. Sou pobre sexo amputado do seu tronco econômico... (Chora) Nunca pensei que a vida fosse resistência." (M,p.17)

Ou

Poeta - "É o sentimento de insegurança do feto na vida aquosa da geração." (M,p.20).

Retorna a sensação de insegurança diante do mundo, mas 
desta vez, por motivos econômicos ou sociais, tanto que o próprio poeta responde a isto: "Não haverá progresso humano enquanto houver a frente única sexual." Define-se assim a oposição entre os dois autores.

2.,Construçāo e destruiçāo no nivel formal

2.1 Linguagem principal e linguagem secundária.

A configuração da obra teatral subdivide-se, segundo Ingarden, em: a. Texto principal, primaz, dá a diretriz dos outros códigos da encenação (visuais, sonoros, auditivos, etc.), é constituído pelas "palavras pronunciadas pelos personagens", e b. Texto secundário, sāo "indicaçōes para a encenação dadas pelo autor". ${ }^{18}$ Portanto o texto secundário se constitui no indice de uma primeira leitura do texto principal, feita pelo autor. Este tipo de texto é muito mais frequente na obra de Nelson Rodrigues: principalmente em Album de Familia e Valsa n.o 6 . Como decorrência disto, observa-se que, para a encenação, sāo fornecitas diretivas precisas, que restringem a "leitura-fruição" tom de univocidade e uma qualidade unidirecional de interpretação do texto. certo que melhor caracteriza a patologia do personagem, mas, por outro, lado, converte a obra num universo fechado.

A preocupação do dramaturgo em assistir aos ensaios de suas peças, em checar a "leitura" que o diretor está fazendo de sua obra, para que não se deturpe, na representação, a sua intenção de autor dramático, corrobora o que dissemos acima.

Em Oswald de Andrade, o texto secundário é pouco frequente, p.e., a segunda cena do $1 .^{\circ}$ ato de $O$ rei da Vela, ou "O país do indivíduo" em $A$ morta, ou ainda toda a primeira cena do $4 .^{\circ}$ quadro de $O$ homem e o cavalo. Como decorrência é favorecida a capacidade criativa do ator, do diretor e a obra se torna muito mais aberta

\subsection{Processo de composição}

Oswald de Andrade utiliza, como processo de composição de suas peças, a justaposição, i.e., a parataxe, em que a coordenação dos atos e quadros oferece relativa maleabilidade de leitura, com possibilidade de modificação na sucessividade dos

(18) INGARDEN, Roman. Les fonctions du langage au théâtre. Poótique, Seuil, Paris, 2(B): $531.538,1971$.

(19) ECO, Umberto. A poética da cbra aberto. In: Obra aberta, S. Paulo. Perspectiva, 1971. p. 4142 (C=leçöo Debates, 4). 
mesmos. Esta flexibilidade permite que, em $A$ morta, se possa antepor "O país da gramática" ao "País do indivíduo", embora, em si mesmos, eles possuam uma sucessividade linear. Tal processo é muito mais evidente em $O$ homem e o cavalo, onde alguns quadros mediais poderiam ser deslocados: na 1. a parte, "Debout les rats", "A barca de S. Pedro", "S.O.S.", e na 2." parte, "A industrialização", "A verdade na boca das crianças", "O tribunal". Isto porque estes quadros não estão presos a uma seqüência cronológica, causal e gradativa. Também temos que admitir que esta possibilidade não é absoluta porque senão negaríamos ao autor a mínima capacidade de organizar e estaríamos defendendo o caos. Dentro, porém, desta relativa possibilidade de reorganização, percebe-se um processo de fragmentação característico da prosa oswaldiana: Serafim Ponte-Grande, Memórias sentimentais de João Miramar, e também de sua poesia (é o simultaneísmo de Mário de Andrade). Tal parcelamento, produto também da intenção paródica de sua literatura, é bem o reflexo de um mundo caótico pós-Primeira Grande Guerra.

Já, em Nelson Rodrigues pelas características de sua posição frente a literatura - instrumento de análise de comportamentos e expressão de seus fantasmas particulares - a linearidade é o processo que casa perfeitamente com a temática a ser desenvolvida. A necessidade do desvendamento linear, gradativo, exige que as cenas apresentadas estejam subordinadas a um eixo central. Mesmo na sua obra mais "caótica", Vestido de noiva, o processo de desvendamento é gradativo: a revelação da identidade da mulher de véu. Não se pode admitir nesta peça a alteração de ordem das cenas, há um nexo causa-efeito que não pode ser rompido.

Os três atos líricos de $A$ morta têm um final simétrico: a morte, a destruiçāo. Em Nelson Rodrigues, a morte geralmente se presentifica no final da peça, seu clímax: BA, AN, AF, VG, SA, F, MP. Ela esteve, porém, em estado de latência durante todo o desenvolver da ação como um prenúncio de sua formalização no final: a mulher grávida moribunda (AF), o morto no acidente (BA), os filhos mortos (AN), Mme. Clessi (VN), e outros.

Em A morta, porém há uma morte simétrica em cada ato: no 1.0 , a Outra, no 2.0 , Beatriz no $3 .^{\circ}$ " "flamba tudo". Até os próprios espectadores são "um imenso cadáver gangrenado".

A principal diferença, porém, está em que o texto oswaldiano é a negação dele mesmo ou seja, no momento em que se 
"flamba tudo", a própria obra é destruída. A morta é metateatro, uma peça ( $A$ morta) dentro de outra peça (a negação da anterior como teatro de introspecçāo romântica e surrealista). Nega-se a peça de ambiente escuro, fechado, de interiorização, de auto-devoramento. Se considerarmos que o que Oswald propõe como teatro verdadeiro é o "de estádio": "Está aí um teatro para hoje, um teatro de estádio... participante dos debates do homem..." ", na linha de Meyerhold e Maiakóvski, verificamos que a peça em questão só se insere na dramaturgia social (izante) de Oswald de Andrade enquanto sua negação, enquanto uma não-peça (assim como Serafim Ponte-Grande é um não - livro). A morta é uma peça de "teatro de câmara" para negar este mesmo "teatro de câmara"'ı". Parece-nos que o personagem- chave desta conclusão a que chegamos acima, é o Hierofante. Ele resume todo o caráter ritualístico (devemos lembrar que seu nome era o do Grande Sacerdote de Elêusis e num sentido figurado "aquele que se presume único conhecedor dos mistérios, das ciências ou das artes") da peça, porque sua figura hierática está presente nos três atos. Ele representa a ideologia assentada, a cultura sedimentada, e o guardião daquela que é considerada a Verdade, única e imutável. Exerce a função de juiz: daí seu distanciamento em cena. "Eu sou a moral." (M,p.7) "Permanecerei fiel a meus propósitos até o final da peça." (M,p.7). "Darei sempre a visão Oficial." (M,p.22). Aparece no $2 .^{\circ}$ ato trazendo um cartaz "onde se lê "Deus, Pátria e Família", está ao lado dos conservadores de cadáveres e rritica a "Massa desprezivel de pronomes mal colocados!" Suas falas no final da peça, caracterizam bem sua filosofia de bolso: "O erro do homem é pensar que é o fim do barbante... O barbante nāo tem fim." Ele é o oponente do Poeta, o revolucionário, que este representa, não pode, no momento do incêndio respeitar aquele, por isso até o Hierofante é queimado. Seu grito de socorro é um gesto de agressão ao público: "Nāo vos pedimos palmas, pedimos bombeiros! (...) Salvai nossas podridões e talvez vos salvareis da fogueira acesa do mundo!"(M.p.56).

Há vários índices no decorrer $d^{\prime} A$ morta que a caracterizam como "teatro épico", pela presença do distanciamento e pela quebra da "quarta parede".

O teatro de Nelson Rodrigues não apresenta, em nenhuma peça, o distanciamento brechtiano. Se, na Valsa $n .^{\circ} 6$,

(20) ANDRADE, Oswald de. Ponta de lança. In: --_-_, Obras completas. Rio, Civilizoçäo Brasilcira, 1972. v. 5, p. 86 (Coleşāo Vera Cruz, Literatura Brasileira. 153)

(21) Ibid., p. 89. 
Sônia se dirige a um espectador, a sua intenção é envolvê-lo emocionalmente, nunca levá-lo a raciocinar, a fim de emitir um juízo crítico. Enfim, é um teatro que se classifica, segundo Brecht, como "dramático".

\subsection{No "pais da gramática"}

$\mathrm{Na}$ "carta-prefácio", Oswald esclarece que $A$ morta "é o drama do poeta". (Isto é corroborado principalmente pelo nível linguístico e pela metalinguagem do $2 .^{\circ}$ ato). Na metalinguagem do $2 .^{\circ}$ ato se coloca em discusão a própria língua instrumental do Poeta. De início se observa uma flagrante oposição da linguagem utilizada no $1 .^{\circ}$ ato e aquela que se utiliza neste "País da gramática". Passa-se da linguagem metafórica, truncada, caótica para uma linguagem alegórica, em alguns momentos, coloquial, ? sempre lógica. Os nomes dos personagens também caracterizam este ato: passa-se da individualização ao coletivo (Os Conservadores, O Juiz, Os Cremadores).

A alegoria linguística que estes personagens representam é bastante clara:

O Polícia - "O mundo é um dicionário. Palavras vivas e vocábulos mortos. Não se atracam porque somos severos vigilantes. Fechamo-los em regras indiscutiveis e fixas (...) Fundamos para isso as academias... os museus... os códigos... (M,p.30).

A imprensa e a política são consideradas as "empresas funerárias" das palavras.

As indicações cênicas (linguagem secundária) obedecem a estas mesmas características: "Juntam-se aos cremadores galicismos, solecismos, barbarismos. Do lado dos mortos cerram colunas graves interjeições, adjetivos lustrosos e senhoriais arcadismos." (M,p.34).

Para quem conhece a história do Modernismo brasileiro e a participação de Oswald na busca de uma língua literária nacional, o texto em questão assume uma maior importância: não apenas metalinguística mas também histórica.

Mas Oswald de Andrade extrapola a convenção gramatical e atribui ao confronto Cremadores/Conservadores a dialética do evoluir humano sobre a Terra: 
Poeta - (referindo-se aos Cremadores) "t a vanguarda que luta pela libertação humana." (M,p.33).

$E$ adquire a violência de ụma radical crítica social e teatral (metateatro).

Cremadores - "O que nos traz à cena é a fome. Mais que qualquer vocação. Muito mais que a vontade de representar. $\mathrm{E}$ o problema da comida! A produção da terra é desviada dos vivos para os mortos. (...) Eles possuem armas e dirigem exércitos iludidos pela ignorância e pela fé religiosa."(M,p.35).

a passagem das catacumbas líricas para as catacumbas politicas.

O “drama do poeta" não é apenas sexual ou existencial, é também formal, como o denuncia Horácio, ao tentar impedi-lo de partir com Beatriz: "Deixa-a! Não vês que habitas de novo com ela os subterrâneos da vida interior?"(M,p.32).

Em Nelson Rodrigues, nada encontramos para que se pudesse estabelecer um cotejo ccm o que se expôs acima.

\subsection{Dialogaçāo}

Os diálogos Posta-Beatriz, em qualquer dos atos de $A$ mor$t a$, são um processo de reiteração dialética. E parece-nos que a proposição de Oswald era esta mesma: a impossibilidade de diálogo-encontro entre o poeta social e a musa-sexual romântica. Em todos os seus diálogos, o movimento é o mesmo: súplica de Beatriz e recusa do Poeta, até a recusa-libertação final.

No $2 .^{\circ}$ ato, a linguagem retórica dos personagens se opõe à semântica da ação.

Poeta - "Não. O coração acorda de repente. E começa o trabalho irracional. Corrosivo de todo debate... A consciência torna-se um estado sentimental e a justiça foge do mundo... Oh! drama!

Desenvolvimento do próprio ser universal! Eu te busco!

Beatriz - "Porque crias em mim pesados encargos assim! E o sentimento de culpa! Desenvolvido 
na célula de um circo. O sentimento espetacular da culpa!

A disciplina das feras, as grandes quedas sem rede, o amor pelo palhaço." (M,p.33).

Esta alternância é justificada pela própria estrutura da peça: a angústia do poeta, dilacerado entre a alma individual e o ser social, entre a alma (conteúdo) e a forma, entre o indivíduo e o coletivo, entre a acomodação (Morte $\mathrm{p} /$ o Poeta, Vida $\mathrm{p} /$ Beatriz) e a rebeldia (Vida $\mathrm{p} /$ o Poeta e Morte $\mathrm{p} /$ Beatriz).

Quanto a Nelson Rodrigıes, sua dialogação é extremamente coloquial, mas tem apenas função referencial e objetiva, é lógica, é denotativa. Em A Valsa $n .^{\circ} 6$ há determinados momentos em que escorrega para o retórico:

Sônia - "Senhora, existe ou existiriam espelhos? Ou, então conheceis a água translúcida de um rio? Um rio, sim, onde meu rosto possa deitar-se entre as águas?" (V6 p.141).

Isto a par de uma linguagem predominantemente coloquial: "Pois é, homem casado! Casadinho! E está direito? Claro que não, evidente, onde já se viu? Essa é muito boa!" (V6, p.143).

E a dialogação, em linguagem coloquial, cotidiana, é talvez a maior contribuição de Nelson Rodrigues ao teatro nacional. Porque "a retórica da geração anterior, geralmente subliterária (quebrada apenas em livros por Oswald de Andrade) deu lugar à especificidade cênica do diálogo."

\subsection{Paródia}

Esta é a característica fundamental da obra oswaldiana. E o elemento diferenciador de maior importância neste cotejo Oswald-Nelson.

A paródia é um processo de destruição de um texto primitivo para reconstrui-lo, modificado. (E portanto o ponto que mais de perto toca ao tema deste trabalho). "A Não-Correspondência entre a informação textual e a subtextual cria sentidos complementares. Deste modo, o crédito do texto é desta maneira DESTRƯfDO. As paródias literárias são construídas sobre este tipo de base." 23

(22) Magaldi, p. 211.

(23) LOTMAN, Ju. M. \& PJATIGORSKIJ, A. M. Le texte of sa fonction. Change, Paris, (14):213, 1973. 
Assim sendo, enumeremos alguns aspectos paródicos do texto $A$ morta:

a. A obra é uma paródia socializante e às avessas da $D i$. vina Comédia de Dante. Em "O país da gramática" Horácio é o guia esviritual e intelectual do Poeta. A troca de Virgilio (do original) para Horácio justifica-se pelo fato de que, este último, propugnava por uma poesia utilitarista:

"Omme tulit punctum qui miscuti utile dulci Lectorem delectando, pariterque monendo".

(Arte Poética)

b. Há paródia à linguagem romântica do "mal-du-siècle" novecentista e à linguagem surrealista. São frases altamente retóricas, sem nexo aparente, fruto de um processo subconsciente de relação, o que a torna hermética e nada comunicativa:

A Outra - Somos um colar truncado...

POETA - Quatro lirismos...

Beatriz - E um só lírio doente...

Poeta - Num pais dissociado (M, p. 14).

O evoluir da ação justificará mais tarde o sentido destas falas, mas elas não têm um prosseguimento lógico. Os próprios personagens são dissociados pela arquitetura cênica: o ator, a marionete, o microfone.

O tom operistico-sentimental do $1 .^{\circ}$ ato está marcado por expressões italianas, dando grande efeito de estranhamento ao texto: "Chi lo sá! Bon giorno!"

c. Paródia à literatura, de um modo geral:

à Damas das Camélias (personagem romântica).

- à "Mosca Azul" de Machado de Assis (poema parnasiano).

- o Urubu de Edgar, retirado do poema de Edgar Allan Poe, "O Corvo", ridicularizado no popular "urubu". Poe, "O Corvo", ridicularizado no popular "urubu". Sua presença no "País da anestesia" parece estar justificada pelo fato que ele apenas conhecia uma expressão "Nevermore" (nunca mais).

d. Paródia às atitudes $\mathrm{e}$ hábitos dos gramáticos, dos acadêmicos e dos puristas da linguagem: 
e. Paródia à conduta e pensamento de determinados representantes da Sociedade: a Senhora Ministra, O Atleta Completo, O Radiopatrulha.

O tom paródico e irônico marca inconfundível da obra (e do caráter) de Oswald de Andrade representa, para o filósofo alemão Friedrich Schlegel, "a clara consciência da eterna agilidade da plenitude infinita do Caos". E a percepção aguda do artista que penetra o outro lado dos seres, fatos e objetos, em busca de captar a mutabilidade e efemeridade do Universo. a atitude inovadora inaugural, desbravadora. Desvenda ao mundo o lado dcsconhecido do Universo. E este desvendamento é a essência mesma da vanguarda, do "estar à frente de seu tempo". Justifica o porquê de, mesmo tendo escrito sua obra cronulogicamente mais cedo do que Nelson Rodrigues, ela ultrapassa o tempo e se projeta ainda hoje, como um texto de vanguarda, como um desafio à nossa percepção e ao nosso conceito de texto teatral.

\section{Conclusão}

Esperamos haver demonstrado no decorrer desta exposição como, de grandes semelhanças, Oswald de Andrade e Nelson Rodrigues, terminam se colocando em oposição frontal quanto ao seu modo de representar o Universo e seu conceito poético. Se Nelson Rodrigues leva a vantagem de ser mais facilmente encenável, Oswald d'Andrade, em Am orta, demonstra seu vanguardismo textual. E o desafio, lançado em 1937, continua a instigar a criatividade de leitores e encenadores porque as possibilidades organizacionais do texto oswaldiano não foram ainda esgotadas.

\section{REFERENCIAS}

ABEL, Lionel. Motateafro: uma visão nova da forma dramática. Rio, Zahar, 1968.

AGUIAR E SILVA, Victor Manuel de. Teoria da lireratura. 2 ed. Coimbra, Almedina, 1969. ANDRADE, Oswald de. Obras completas. ?̦io, Civilização Brasileiro, 1972-1974 (Coleção Vera Cruz, Literatura Brasileira, 147).

BROW, Norman. Vida contra morte. Petrópolis, Vozes ,1972 (Coleçāo Contraculfura, 2) ECO, Umberto. Obra aberta. S. Paulo, Perspectiva, 1971 (Coleção Debates, 4)

INGARDEN, Roman. Les fonctions du langagn au théâtre. Pob́tiquo, Seuil, Paris, 2(8): 531$-538,1971$.

LOTMAN, Ju. M. \& PJATIGORSKIJ, A. M. le texte el sa fonction. Change, Paris, (14): 212.218, 1973.

MAGALDI Sábato. Panorama do teatro brasiloiro. S. Paulo, Difusão Européio, 1962 (Corpo e Alma do Brasil, 9).

POE, Edgar Allan. Poesia o prosa. P. Alegre, Globo, 1944 (Biblioreca dos Séculos) 
PRADO, Décio de Almeida. Apresentaçāo do teatro brasileiro modomo: crítics leatral (1947-1955). S. Paulo. Martins, /1956'

READ, Herbert, FRANCASTEL, Pierre \& BRECHT, Bertold. Sosiologia da arte-lll. Rio, Zahar, 1967 (Textos Básicos de Ciências Socizis).

REVISTA DE Cultura Vozes. Petrópolis Vozes, 68(1), jan/fev. 1974.

RODRIGUES, Nelson. Teatro quase completo. Rio, Tempo Brasilciro, 1965. 4v.

ROSZAK, Theodore. A contracultura. 2 ed. Petrópolis, Vozes, 1972 (Coleçāo Contraculiura, l)

TELLES, Gilberto Mendonça. Vanguarda curopóia e modernismo brasileiro. Petrópolis, Vozes, 1972. 